\title{
Regulation of stress-strain state and calculation of deformations of continuous foundations under increased multiple loads
}

\author{
Anatoliy Butenko ${ }^{1, *}$, and Oleg Gerasimenko ${ }^{2}$ \\ ${ }^{1}$ TOV Trans Stroj Komplex (LLC under the laws of Ukraine), Simferopolskiy off st. 6, 61052 \\ Kharkiv, Ukraine \\ ${ }^{2}$ Ukrainian State University of Railway Transport, Building Materials and Structures Department, \\ Feuerbach sq. 7, 61050 Kharkiv, Ukraine
}

\begin{abstract}
The analysis of design and operation experience of grain elevators is executed. Metal silos of high capacity are representatives of structures with continuous foundations that perceive increased and multiple loads. Methods of regulating the stress-strain state with the help of creation of artificial bases are considered in detail. A technique for estimating the stress-strain state and calculating the deformations of continuous foundations is proposed.
\end{abstract}

The development of agricultural industry in Ukraine has caused the need for developing infrastructure. Currently, the construction of railway transfer platforms for crops and other loose products and materials is a vital area. Such products are stored in silo-type elevators using high-capacity metal silo towers.

The dimensions of such structures determine the dimensions of foundations. Generally, flat bottom silos, which are the most loaded, are constructed with the following types of foundations:

- natural foundations;

- $\quad$ piled foundations;

- $\quad$ artificial foundations.

Natural base is used for continuous foundations in rare cases, due to the fact that the design resistance of soil is extremely limited. For instance, with an approximate height of the silo of 25 meters and with the corresponding volume of product, the load will be approximately 20 tons $/ \mathrm{m}^{2}(0.2 \mathrm{MPa})$. After taking into account the dead load of the foundation, the silo and its technological equipment as well as other loads (snow, etc.), the total load on the foundation is over 30 tons $/ \mathrm{m}^{2}(0.3 \mathrm{MPa})$. Only certain types of soils can carry such loads.

Piled foundations are extremely expensive and they increase the construction time. Besides that, the construction of piled foundations is not always efficient and justified. While choosing the foundation type, one of the criteria is availability and position of support ground, which determines the length of the poles and influences both economic

* Corresponding author: butenkoanatoliy@gmail.com 
rates and reliability of the foundation. The distance between poles is impossible to decrease, even if the bearing capacity of poles is high enough to carry the load of the foundation, since the stiffness and strength parameters of the grill are limited.

The most interesting foundations are artificial, including foundations with ground (sand or crushed stone) beds, and also foundations on stabilized soil, reinforced soil and strengthened soil with the help of jet grouting. Soil stabilization is increasing bearing capacity of soil with several methods: mechanical (tamping), dewatering [1, 2], injection, thermal (calcinating, freezing). Injection methods of soil stabilization assume the injection of hardening materials into the soil (including chemical methods - cementation, silicification, tarring).

Large part of the territory of Ukraine is in difficult soil conditions for construction and maintenance. One of the most important tasks is providing reliability and durability of foundations. The difficulty of soil conditions is illustrated by loose unstable soils, covering major territories. Loose or unstable soils are the ones that drastically change their structure due to additional external factors and cause significant subsidence. Structural breakdowns of these soils happen under physical or mechanical stresses. Structurally unstable soils are clayey, collapsible forest soils, the ones that constrict heavily while soaking. Such soils deform easily, which leads to large subsidence and cause additional expenses for maintenance and strengthening.

Limits for use of various stabilization methods are determined according to the soil permeability and the properties given to the stabilized soil (table 1).

Table 1. Limits for use of various stabilization methods

\begin{tabular}{|c|c|c|c|c|c|c|c|c|c|c|c|c|}
\hline \multirow{2}{*}{\begin{tabular}{|c|} 
Soil type \\
Soil \\
impermeability, \\
meters per day
\end{tabular}} & \multirow{2}{*}{$\begin{array}{c}\text { Gravel } \\
500\end{array}$} & \multicolumn{5}{|c|}{ Sand } & \multicolumn{2}{|c|}{$\begin{array}{c}\text { Loamy } \\
\text { sand }\end{array}$} & \multicolumn{2}{|c|}{$\begin{array}{c}\text { Aeolian } \\
\text { soil }\end{array}$} & \multirow{2}{*}{\begin{tabular}{c|}
$\begin{array}{c}\text { Loa } \\
\text { m }\end{array}$ \\
0,05
\end{tabular}} & \multirow{2}{*}{$\begin{array}{l}\text { Clay } \\
0.005\end{array}$} \\
\hline & & 100 & 80 & 50 & 20 & 5 & 1 & 0.3 & 2 & 0.2 & & \\
\hline \multicolumn{13}{|c|}{ Efficient stabilization methods } \\
\hline Cementation & \multirow{2}{*}{$\begin{array}{c}\text { stabilization } \\
\text { with strength } \\
\text { from } 0 \text { to } \\
50 \mathrm{MPa}\end{array}$} & + & + & & & & & & & & & \\
\hline Clay grouting & & \multicolumn{3}{|c|}{$\begin{array}{l}\text { consolidation } \\
\text { with strength } \\
\text { from } 2 \text { to } \\
5 \mathrm{MPa}\end{array}$} & & & & & & & & \\
\hline Silicification: & & & & & & & & & & & & \\
\hline two-solution & & & \multicolumn{6}{|c|}{$\begin{array}{l}\text { stabilization with strength } \\
\text { from } 0 \text { to } 5 \mathrm{MPa}\end{array}$} & & & & \\
\hline one-solution & & & & & \multicolumn{4}{|c|}{\begin{tabular}{c|c} 
consolidation \\
with strength \\
from 2 to \\
$5 \mathrm{MPa}$
\end{tabular}} & + & + & & \\
\hline gas & & & \multicolumn{4}{|c|}{\begin{tabular}{c|} 
stabilization \\
with strength \\
from 0 to \\
$5 \mathrm{MPa}$
\end{tabular}} & & & \multicolumn{2}{|c|}{$\begin{array}{l}\text { stabilizatio } \\
\mathrm{n} \text { with } \\
\text { strength } \\
\text { from } 0 \text { to } \\
5 \mathrm{MPa}\end{array}$} & & \\
\hline tarring & & & & & \multicolumn{4}{|c|}{$\begin{array}{c}\text { stabilization with } \\
\text { strength from } 0 \text { to } \\
5 \mathrm{MPa}\end{array}$} & & & & \\
\hline $\begin{array}{l}\text { electrochemical } \\
\text { stabilization }\end{array}$ & & & & & & & & & & & $\begin{array}{r}\text { consol } \\
\text { with s } \\
\text { fron } \\
5 \mathrm{I}\end{array}$ & $\begin{array}{l}\text { idation } \\
\text { rength } \\
2 \text { to } \\
\text { IPa }\end{array}$ \\
\hline
\end{tabular}


Taking this into account, the methods are divided into the following types:

1)rapidly increase mechanical strength and impermeability of soil;

2)provide stabilized soils with impermeability only;

3)increase water resistance and thickness of soil (dewater clayey soil and muck).

Table 1 shows that cementation should be used to provide soil stabilization for gravel and sandy soils with soil permeability index from 80 to 500 meters per day. Lower limit is characterized by coarse sands, which can be penetrated by modern cement.

In order to give impermeability to sandy soils, where we cannot use cement, it is replaced with silicate and clay-silicate solutions, which can provide impermeability for sandy soils with permeability index from 20 to 100 meters per day. Sandy soil is stabilized by two-solution silicification. This method is viable for soils with permeability index from 2 to 80 meters per day.

A number of one-solution silicification methods (with phosphoric acid, sulfuric acid and aluminum sulfate, sodium aluminate, etc.) can be used in sandy soils with permeability index from 0.5 to 5 meters per day. For the most part these methods provide soils with impermeability. The method of one-solution silicification using hexafluorosilicic acid provides sandy soils with strength and impermeability and can be used for soils with permeability index from 0.2 to 20 meters per day.

This method allows for the improved formulas with increased penetration capability and strength to be used [3-6]. The method of one-solution silicification, which involves chemically active substances from the soil itself, is used to stabilize collapsible forest soils. This method is used for collapsible soils with impermeability index from 0.2 to 2.0 meters per day, where the soil dampness is below $17 \%$, which means that the forest has to be located above ground water level. With higher dampness, approx. 20-22\%, gas silicification is used. First, the soil is injected with carbon dioxide, then silicate, and again carbon dioxide. These processes can be only performed by experienced professionals. As a result of gas silicification, the soil gets strength and water resistance.

Stabilization of sandy soils combined with providing impermeability is achieved with the help of tarring, if the soil has impermeability index from 0.5 to 20 meters per day.

Method of electrochemical stabilization allows us to give water resistance to clay soils saturated with water, and, as a result, eliminate soaking and bulging in water. Sphere of use for this method is limited by the following soil impermeability indexes: using two-solution electro-silicification - from 0.05 to 0.2 meters per day, using one-solution electrosilicification - from 0.005 to 0.2 meters per day. Between these limits electric current multiplies the penetration of solution into the soil by $1.5 \ldots 2$.

Stress-strain properties of soils change dramatically during stabilization and the modulus of deformation multiplies by 5-10. So, while choosing the type of soil stabilization and calculating the soil settlement, calculation of stabilized soil footing is performed as if for linearly deformed environment. Preset parameters of stabilized soil are used in the "footing-foundation" design diagram. It is worth mentioning that in case of reconstruction the reverse problem is solved - the adjustment of parameters is made for existing foundation.

Extraordinary complexity of silo foundations consists in operating mode under repeatable load-unload rotations in a relatively short time span [7].

Loose soils under the foundations can lead to the breakdowns in stability of footing. Careful attention should be given to the soils, which are in watered condition, because the soil can change its structure, consistency and lose stability as a result of destruction of bonds. This process is possible for the soils, which are in the zone of footing and foundation or in case of preconsolidation of surface soil levels of footing with further water restraint in soil mass. In a similar situation the most optimal decision will be to strengthen loose or destroyed soils of the footing. 
While strengthening footing soils through injections or with the help of jet grouting, we should consider stress-strain behavior of foundation. There are structural elements with different stiffness properties and different tension under the bottom of foundation, so the head pressure or the depth of jet grouting differs under various structural elements of the foundation as well. It is necessary to take into account the fact that the head pressure value must not exceed the value of design resistance of soils.

Extended foundation and the outlined in the plan foundations deform during stabilization of soils and under work, which determines the overall deformation diagram of the foundation and its stress-strain behavior (SSB) in the future.

The problem of determining SSB comes down to solving complex configuration plate with stiffness characteristics, which differ significantly from one another, on quasi-elastic basis. Stiffness parameters of a large continuous foundation depend on geometrical dimensions (Fig. 1). The value of soil resistance under the bottom of foundation depends on stiffness of the foundation itself and the applied loads, which are different as a result of distribution across the footprint of the structure. There are numerous loads across the foundation: the pressure, transferred from the upper body of the silo (snow load); the dead weight of the upper body of the silo; the load of loose materials on the walls of the silo resulting from friction; the load of the weight of the product applies to the other parts of the silo. There are zones on the footprint of the foundation, which are in quasilinear deformed environment and zones of soil behavior beyond the elasticity limits.
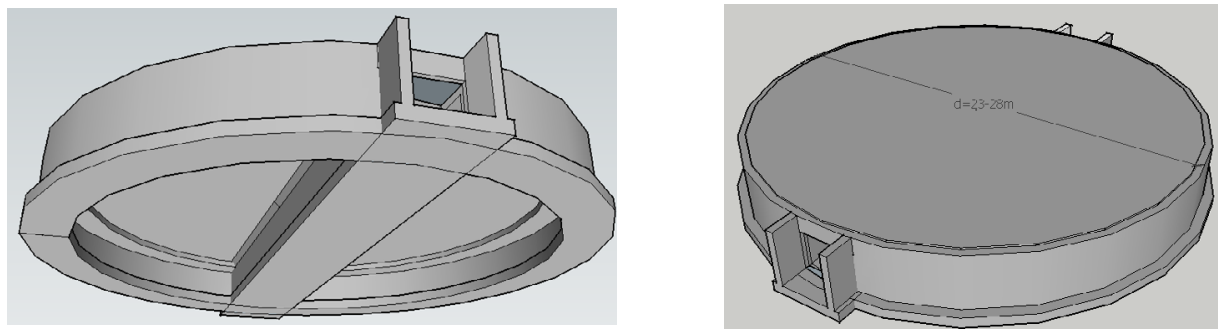

Fig. 1. Exterior design of continuous silo foundation.

The experience in operating existing elevator complexes, and also the results of geodesic monitoring of silo bodies and the experience in observing settlement of foundations [7] show that the modern calculation methods, used in designing, are inefficient. The data, received from calculations, do not match the data of geodesic observations of the settlement of foundations and their structural parts. The usage of finite element models while predicting the settlement of continuous foundations is not enough. For the most part, the reason for this is the approximate estimation of parameters as a result of possible negative processes in soils during operation of foundations or geological properties of soils. Multiple repeatable loads of silos cause additional settlement of the foundations and worsen the condition of soils.

The method of equivalent layer, which takes into account transverse extension of soil unlike the method of gradual summation, is the most reliable method for evaluation and prediction of foundation settlement. With the width of the foundation bottom $b \geq 10 \mathrm{~m}$ and the deformation modulus of soils $E \geq 10 \mathrm{MPa}$ (also allowed to use for soil layers with the deformation modulus $E<10 \mathrm{MPa}$ in compressed soils, if their combined width does not exceed 0.2 from the compressed width) the method of linearly deformed layer is applied. However, increasing the foundation dimensions, which is typical for continuous foundations, decreases the accuracy of settlement calculations.

In order to estimate the settlement and stress-strain behavior of continuous foundations the engineering method based on design principles of DBN (National building code) B.2.1- 
10-2009 [8] is suggested. This method takes into account structural features of large silo foundation, mutual influence of neighbor parts of the foundation in proportion to tension under their footing and stiffness of the foundation, calculations of settlement under specific areas of foundations. In order to estimate SSB we should also consider stiffness of foundation basis and prestress caused by the injection of solutions for soil strengthening.

\section{References}

1. A.M. Plugin, O.S. Gerasimenko, S.V. Miroshnichenko, Plugin A.A., Collected scientific works of Ukrainian State University of Railway Transport, 63, 63-69 (2004)

2. A.M. Plugin, A.A. Plugin, O.S. Gerasimenko, Collected scientific works of Ukrainian State University of Railway Transport, 77, 162-175 (2006)

3. A.N. Plugin, A.A. Plugin, L.V. Trikoz, Collected scientific works of Ukrainian State University of Railway Transport, 87, 108-120 (2007)

4. A.N. Plugin, O.S. Gerasimenko, L.V. Trikoz, A.A. Plugin, Naukovii visnyk budivnitstva, 48, 154-162 (2008)

5. O.S. Gerasimenko, Increasing the penetration capability and strength of liquid glass (Kharkiv, UkrGAZHT, 2008)

6. O.S. Gerasimenko, A.A. Plugin, A.M. Plugin, L.V. Trikoz, Composition of liquid glass, patent UA87795C04B28/26 (2009)

7. A.A. Butenko, O.V. Kichaeva, Suchasni tehnologii ta metodi rozrahunkiv u budivnytstvi. Collection of scientific articles, 5, 308-315 (2016)

8. Footings and foundations of buildings. Basis principles of structural design. DBN (National building code of Ukraine) B.2.1-10-2009, (Kyiv, 2009) 